\title{
DESENVOLVIMENTO DISCENTE E IDENTIDADE PROFISSIONAL DE ENFERMAGEM: OS SISTEMAS DE CONCEITOS COMO MEDIADORES DO APRENDIZADO
}

\author{
DISCENT DEVELOPMENT AND NURSING PROFESSIONAL IDENTITY: THE SYSTEMS \\ OF CONCEPTS AS LEARNING MEDIATORS \\ DESARROLLO DISCENTE E IDENTIDAD PROFESIONAL DE ENFERMERIÁ: LOS \\ SISTEMAS DE CONCEPTOS COMO MEDIADORES DEL APRENDIZAJE
}
Cilene Aparecida Costardi Ide ${ }^{1}$ Camilla Alexsandra Schneck ${ }^{2}$

\begin{abstract}
RESUMO: O estudo tem como foco a caracterização de representações socialmente constituidas acerca dos conceitos "Enfermagem" e "Enfermagem e contexto". Metodologicamente, os esquemas mentais interpretativos foram seqüencialmente configurados no decorrer da Graduaçāo a partir das respostas escritas pelos mesmos estudantes às seguintes questōes: como você conceitua Enfermagem e qual a relação entre a profissão e o contexto socialę Utilizamos esquemas de interpretação pautados na análise de conteúdo. Como resultado. identificamos um desenvolvimento peculiar de esquemas conceituais formalizados mediante estruturas que evoluiram tendo o sistema formador e o sistema utilizador de recursos humanos como referência, promovendo perspectivas distinias de atuação profissional. Os núcleos constituintes de cada etapa de concepçāo expressaram uma estrutura lógica e incorporada à construção posterior configurando uma evolução determinada pela adesão seletiva das estudantes d̀ graduaçāo ou ao campo de prática. Houve ainda um movimento à margem desses dois sistemas decorrente da discrepância entre essas experiências e os esquemas pessoais.
\end{abstract}

PALAVRAS-CHAVE: Sistemas de conceito - Processo ensino-aprendizagem

ABSTRACT: The focus of this study is characterisation of the representaions socially constituted about the concepts "Nursing" and "Nursing and contexi". The interpretative mental schemes were sequentially configured during the Graduation course starting from the written answers supplied by students to the following questions: "How do you judge Nursing?" and "What is the relation between the profession and social context? "We have used interpretation schemes based on the containts analysis. As a result, we have identified a peculiar development of schemes formed by means of structures that were involved with forming system and used system of human resources as reference which promote distinct perspectives of professional performance. The components nucleuses of each stage of conception expressed the logical structure which were incorporated to subsequent construction, that configures a evolution determined by selective adhesion of students to the graduation or to the practice field. There has been a movement alongside to those systems resulting from discrepancy between the experience and personal schemes.

KEYWORDS: Concept system - Teaching-learning process.

\footnotetext{
${ }^{1}$ Professora Titular do Departamento de Enfermagem Médico - Cirúrgica da EEUSP. Pesquisadora do CNPq.

${ }^{2}$ Aluna de Graduação em Enfermagem da EEUSP - Bolsista do CNPq.
} 
RESUMEN: El estudio tiene como foco la caracterización de representaciones socialmente constituidas acerca de los conceptos "Enfermería" y "Enfermería y contexto". Metodológicamente, los esquemas mentales interpretativos fueron secuencialmente configurados en el decorrer de la Graduación a partir de las respuestas escritas por los mismos estudiantes a las siguientes cuestiones: Como usted conceptua Enfermería y cual es la relación entre la profesión y el contexto social?. Utilizamos esquemas de interpretación pautados en el análisis de contenido. Como resultado. identificamos un desarrollo peculiar de esquemas conceptuales formalizados mediante estructuras que progresaron teniendo el sistema formador $y$ el sistema utilizador de recursos humanos como referencia. promoviendo perspectivas distintas de actuación profesional. Los núcleos constituyentes de cada etapa de concepción expresaron una estructura lógica e incorporada a la construcción posterior. configurando una evolución determinada por la adesión selectiva de las estudiantes a la graduación o al campo de practica. Hubo todavia un movimiento al márgen de esos dos sistemas decorrente de la discrepancia entre esas experiencias y los esquemas personales.

PALABRAS CLAVE: Sistemas de concepto - Proceso de enseñanzo-aprendizaje

\section{INTRODUÇÃO}

Um dos grandes desafios para o sistema de ensino superior é desenvolver meios e formas de reconhecer, transformar e potencializar o desenvolvimento pessoal e os processos de aprendizagem de seus estudantes, identificando a natureza conceitual, bem como os atributos constitutivos da identidade profissional em formação.

Nesse sentido, a maneira como estudantes de Enfermagem percebem e agem em relação à Graduação tem sido objeto de nossa atenção como parte do projeto "Enfermagem e o processo ensino - aprendizagem" (Ide e Noda, 1995).

Esse investimento no reconhecimento do processo de formação, com o intuito de identificar esquemas mentais interpretativos enquanto manifestações de aprendizado, pressupōe explicitar seus referenciais teóricos expressos a seguir:

- pela educação formal, o pensamento lógico reelabora-se no sentido de superar os elementos subjetivos e pessoais que ainda conserva de suas origens, passando a ter, como baliza, as atividades (processos) e os conhecimentos socialmente constituídos, aplicados a determinados fins e açōes profissionais (Ratner, 1995);

- esse processo de interiorização dos principios do arbitrário cultural da graduação tem o poder de produzir um "habitus durável", capaz de perpetuar-se após a cessação da ação educativa. Produziria e reproduziria a integração intelectual e moral do estudante ao seu grupo profissional (Bourdieu e Passeron, 1996); 
- a generalidade de operações cognitivas inerentes a essa ação educativa abrange todo o espectro dos conceitos e capacidades individuais que se constituem no decorrer da Graduação, formando-se quando se pensa a respeito de coisas específicas;

- o nivel específico de abstração desse processo cognitivo decorreria da sustentação técnica dessa ação educativa, incluindo processos de dedução, compreensão, evolução de noções, interpretação de causalidade, culminando no domínio peculiar das práticas e dos códigos de atuação profissional (Vygotsky, 1991 a e b);

- a internalização dos valores, dos conceitos e dos princípios de ação inerentes à formação profissional caracterizam ritmos e formas peculiares de desenvolvimento discente. Essa evolução decorre de mecanismos relativos de adesão, valoração, assimilação e transformação dos conteúdos da graduação (Vygotsky, 1991 a);

- em sintese, esse processo pessoal de reconstrução da realidade se manifesta, inclusive, pela elaboração de novos sistemas de conceitos e de ações que teriam na percepção e concepção da profissão sua expressão essencial.

Frente a esse quadro teórico e tendo a generalidade e a particularidade desse processo de formação dos sistemas de conceitos e de ações como questão empirica, estabelecemos como objetivos para esse estudo:

- identificar aspectos do capital sócio-cultural dos estudantes participantes da pesquisa;

- caracterizar o desenvolvimento dos sistemas de conceitos "Enfermagem como profissão" e "Enfermagem e contexto social".

\section{METODOLOGIA}

Local e sujeitos - O estudo foi desenvolvido junto a oito estudantes da Escola de Enfermagem da USP ingressantes no ano de 1994, constituintes da primeira turma a cursar o novo currículo de Graduação. Essa coleta foi seriada, ocorrendo seqüencialmente, junto aos mesmos estudantes, ao final de cada um dos semestres letivos profissionalizantes. Participaram do projeto os alunos que, após a inclusão por sorteio na primeira coleta, aceitaram continuar constituindo o grupo.

Coleta de dados - Em função da natureza qualitativa da indagação, os dados foram seqüencialmente coletados por meio de entrevista semi estruturada com os estudantes, tendo as seguintes questões norteadoras: 
- tendo como base sua própria elaboração bem como os conteúdos das disciplinas da Graduação, como você conceitua a profissão Enfermagem?

- que relações você identifica entre a Enfermagem e o contexto social ?

A trajetória pessoal desses estudantes, bem como aspectos da bagagem sócio-cultural foram identificadas, tendo como instrumento o modelo elaborado por Rodrigues (1978), agregando a configuração da estrutura familiar: composição, origem, trabalho, formação escolar, hábitos de vida, vinculação religiosa, política, dentre outras formas de atividades gregárias.

Análise dos dados - Para análise dos dados obtidos foram utilizados esquemas de interpretação pautados na análise do conteúdo conforme proposta de Bardin (1977). Agregou, por decorrência metodológica, o recorte e escolha das unidades de registro, 0 inventário e a configuração das categorias resultantes dessa classificação analógica e progressiva dos elementos constituintes dos conceitos elaborados.

\section{RESULTADOS}

Esse trabalho agregou etapas relativas à vivência discente do $1^{\circ}$ ao $7^{\circ}$ semestres letivos e foi desenvolvido em duas etapas. A primeira fase eqüivaleu ao desenvolvimento das disciplinas Introdução à Enfermagem ( $1^{\circ}$ semestre letivo); fundamentação do processo de cuidar $\left(2^{\circ}\right.$ semestre $)$ e a primeira inserção a uma das 4 áreas assistenciais ( $3^{\circ}$ semestre ). Esses dados constituíram o conteúdo de um trabalho já elaborado (Ide e Noda, 1995). A segunda fase do estudo, com dados inéditos, abrange os depoimentos do mesmo grupo de estudantes a partir da inserção às demais disciplinas profissionalizantes, ou seja: as três outras áreas temáticas assistenciais $\left(4^{\circ}, 5^{\circ}, \mathrm{e}\right.$ $6^{\circ}$ semestres), culminando, no $7^{\circ}$ semestre, com a vinculação às disciplinas de Administração em Enfermagem III, Enfermagem em Terapia Intensiva e Enfermagem em Saúde Coletiva; Fundamentação e Prática.

Os dados obtidos configuraram aspectos significantes na conformação dos sistemas de conceitos desse grupo de discentes, na sua aproximação com a Enfermagem, apreendida numa dupla perspectiva: o da concepção da profissão em si, bem como a elaboração da inserção dessa atividade no contexto, num prisma de externalidade.

Antecedendo a caracterização desse processo elaborativo, cabe identificar aspectos do capital sócio - cultural desses alunos enquanto grupo. Nesse sentido, tendo as categorias propostas por Rodrigues (1978); como baliza, identificamos uma configuração expressa a seguir. 
O Grupo participante: traços de um perfil.

QUADRO 1- CARACTERIZAÇÃO DA BAGAGEM SÓCIO-CULTURAL DO GRUPO.

\section{Categorias}

\section{Configuração familiar}

- uma migração limitada aos avós, no sentido de outros estados para Săo Paulo.

- um núcleo familiar atual: de porte médio (dois a três irmãos); com todos os filhos estudando; tendo os pais vinculados a atividades de comércio, com renda suficiente para custear o ensino superior desses estudantes (entre 6 a 9 salários-mínimos). Todos referindo serem católicos.

\section{Configuração discente}

- alunos jovens (apenas uma com mais de 30 anos), católicos, cinco dos quais já trabalharam anteriormente;

- alunos sem vinculação a entidades ou grupos associativos;

- alunos com um padrão de lazer direcionado ao cinema, ao shopping, a ouvir música e a dançar.

Podemos considerar, portanto, um grupo em sintonia com os padrões sócioculturais da maioria dos estudantes de graduação vinculados às Unidades de Ensino Públicas (Wakamae, 1989). Padrōes que, não configurando indicadores de exclusão, caracterizam uma bagagem sócio-cultural limitada, vinculada a hábitos que não teriam acesso a um lazer mais elaborado, assim como relação social que não contempla atividades de vinculação associativa, inclusive a politica.

\section{Os esquemas mentais interpretativos: a construção do sistema de conceitos}

\section{Síntese dos dados preliminares ( $1^{a}$ fase )}

- uma elaboração preliminar, reiterativa e à semelhança de conteúdos da disciplina introdutória, expressa em sintonia com o discurso oficial, já privilegiando alguns conteúdos, porém sem manifestações pessoais acerca da questão em pauta. Repete - se a abordagem macrodinâmica, bem como o perfil social da prática à semelhança do ideário adotado;

- uma etapa subseqüente caracterizada pelo afastamento dos núcleos temáticos presentes na primeira concepção e pelo inicio da confrontaçäo entre representações e expectativas da ação apriorísticas anteriores à graduação e aos códigos profissionalizantes. Emerge um projeto do vir a ser enfermeiro híbrido, tendo como anteparo tanto a imagem do médico quanto o modelo leigo, sintonizados em valores pessoais. Evidencia-se um vínculo com a busca de um saber e um fazer voltado para o cuidar de um ser 
biopsicossocial ou para o administrar na perspectiva de direcionar a atuação. A dimensão de externalidade atribuída à profissão é negada e reduzida à relação do doente ao seu contexto de vida, modificado pela doença. Esses depoimentos identificam valoração, seleção e início de uma viabilização de projetos que teriam sintonia às demandas, concepções e expectativas de atuação pregressas e que serviriam como filtro para os códigos da graduação;

- uma terceira etapa marcada pelo impacto crescente provocado pela inserção em diferentes campos de prática. Outro núcleo temático significante relaciona-se à valorização do cuidar ciência (conhecimentos, competência), cuidar valor (sacrifício, abnegação) e do cuidar atitude (responsabilidade, prontidão).

A construção dos sistemas de conceitos discentes ( $2^{\mathrm{a}}$ fase )

Esquema 1: Núcleos constituintes do conceito Enfermagem: o embate de referenciais.

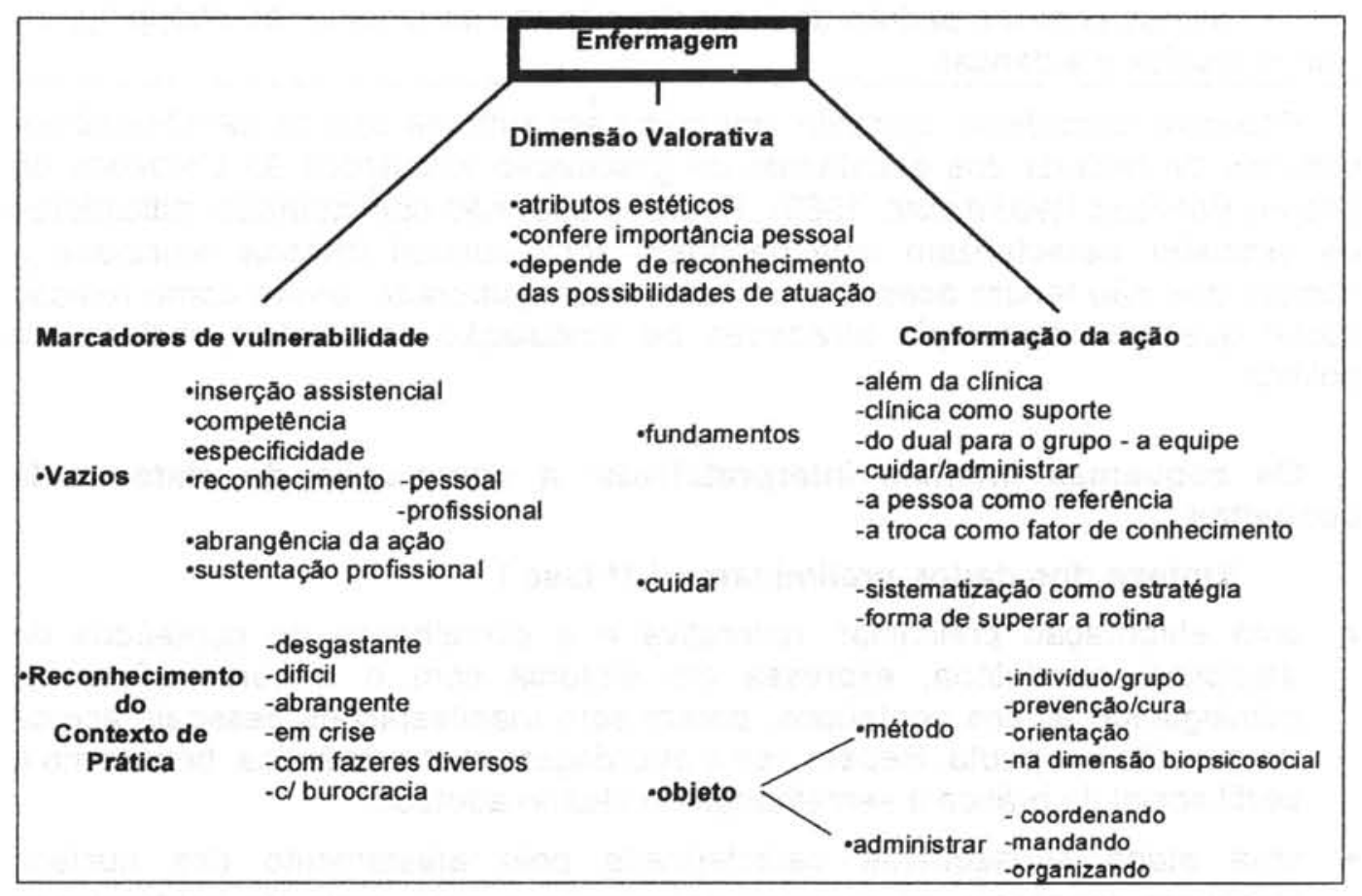

Essa representação do que seja Enfermagem decorreria de uma seleção de conteúdos, de experiências e de percepções relevantes sob o prisma de cada estudante e que funcionariam como matrizes de compreensão e de projeção de possibilidades de re - ação no contexto de prática. 
Os núcleos identificados sustentam uma elaboração cognitiva capaz de identificar, nomear, valorar e atribuir significados inerentes ao processo de ação tendo, nesse sentido, um poder estruturante capaz, inclusive, de nortear a proposição da atuação. Entretanto, merece destaque tanto a intensidade e a lucidez na identificação dos pontos de vulnerabilidade, tendo a prática como princípio de realidade, quanto a existência de uma dimensão valorativa em aberto, dependente do interjogo entre projetos pessoais e a realidade apreendida.

No que se refere ao conceito Enfermagem e contexto, o processamento de conteúdos vem caminhando no sentido de delimitar o espaço e ação profissionais, tendo as condições objetivas da prática como elemento determinante.

\section{Esquema 2: Núcleos constituintes do conceito Enfermagem e Contexto: a nocão de acão e espaco profissionais}

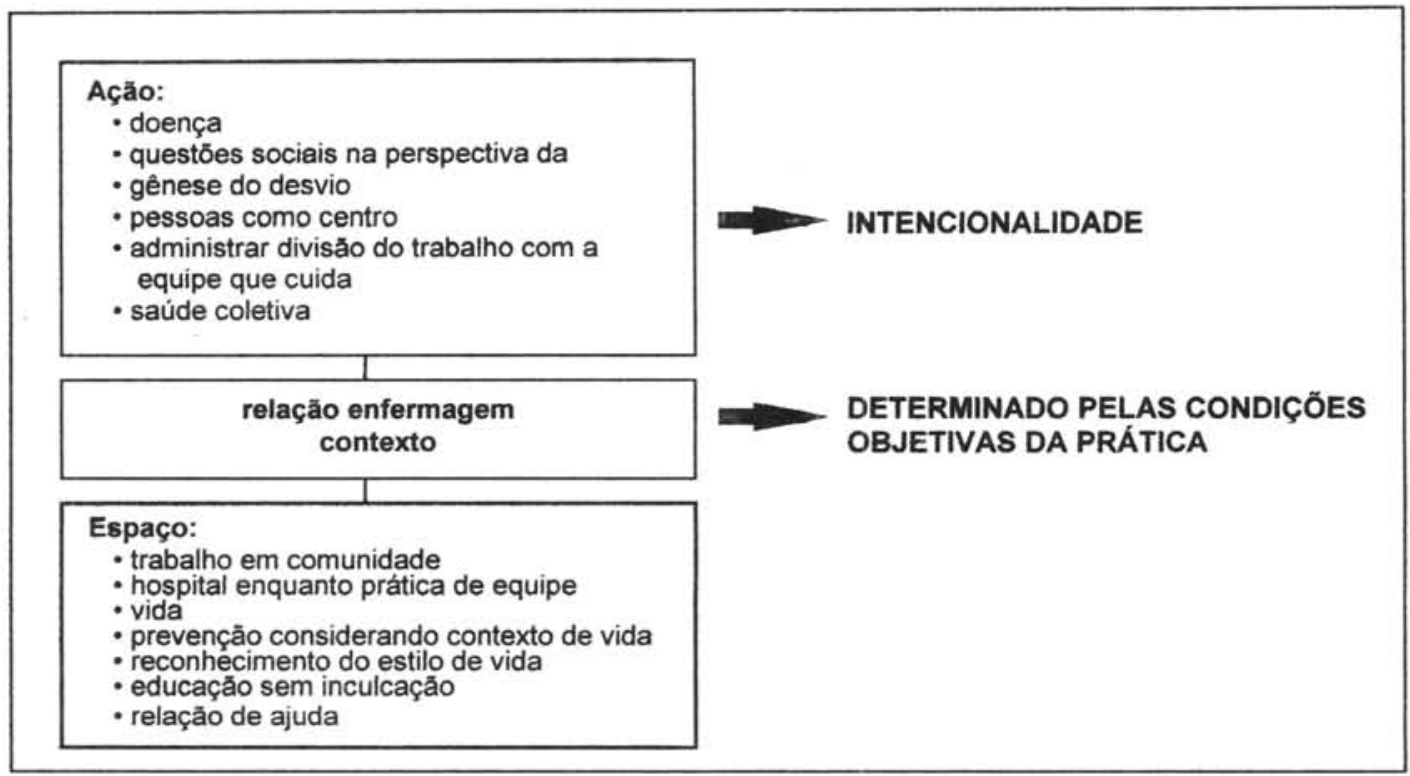

Seqüencialmente, tendo uma mesma direção e sentido, os esquemas de conceitos, ao final do $5^{\circ}$ e $7^{\circ}$ semestre letivos, caminharam reafirmando os núcleos já identificados. Assim, o processamento do conceito Enfermagem vem evidenciando um universo simbólico de significações abordado em dois campos distintos. Nessa construção, o real e o ideal se interpõem e contraditoriamente se complementam enquanto perspectiva da superação, deixando em aberto uma escala valorativa dependente de viabilização de expectativas e de possibilidades da superação. 
Esquema 3: Conceito Enfermagem: limites e perspectivas de acão

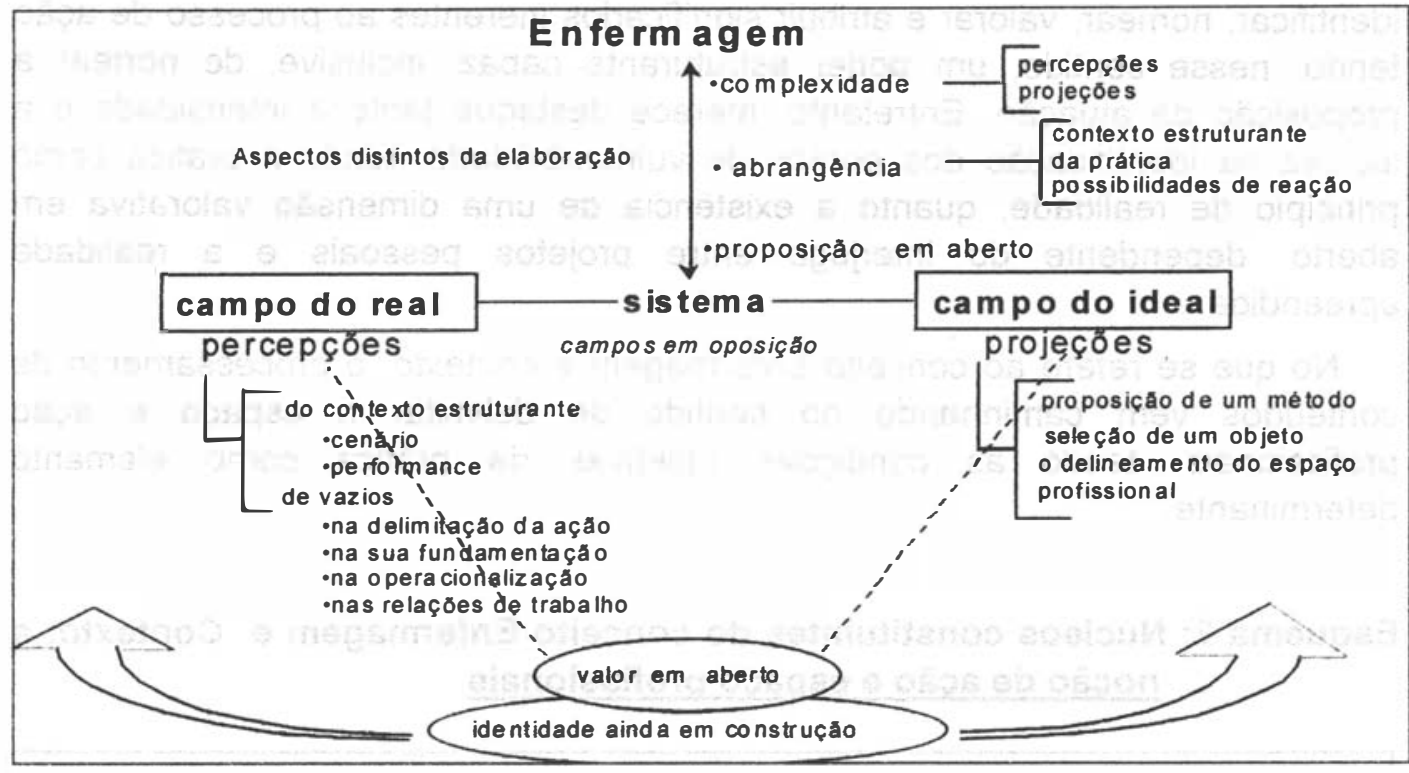

Aderidos ao ideário da Enfermagenı enquanto construção calcada no ideal, estudantes expressam um pensamento generalizante, estruturando o conceito a partir: da delimitação do espaço profissional como princípio de especificidade de atuação; da definição dos objetos cuidar - para além da técnica, tendo a pessoa reconhecida na sua dimensão biopsicossocial como foco - e administrar, investido com poder de mando e de ordenação do contexto. Complementando, acrescentam ao conceito um atributo teórico operacional enquanto intervenção fundamentada e sistematizada a se viabilizar na dependência da superação da rotura do cuidar em série, do cuidar esvaziado de ciência, do cuidar taylorizado.

No contraponto, reagindo às experiências do cotidiano, identificam e expressam nuanças sombrias do contexto profissional, acrescentando ao conceito Enfermagem marcadores de vulnerabilidade relacionados às condições em que essa prática se desenvolve, qualificando-a como difícil, desgastante, árdua. Identificam, ainda, vazios no que se refere à identidade profissional (competência, especificidade, espaço profissional, reconhecimento) e à fundamentação dessa atuação considerada pouco elaborada e limitada frente à abrangência da atuação.

Como terceiro núcleo constituinte desse conceito, emerge uma categorização valorativa da profissão, agregando atributos dependentes da viabilização de projetos com força de superação enquanto investimentos, passiveis de promover reconhecimento e valorização pessoal. A perpetuação da performance no cenário vigente teria um poder desestruturante capaz de desqualificar e de desvalorizar a profissão. Nessa elaboração, a condição determinante do modelo de atuação parece se sobrepor à intencionalidade dos sujeitos enquanto instrumento de reconhecimento e de identificação de perspectivas de ações. 
Também no que se refere à elaboração do conceito Enfermagem e contexto estaria ocorrendo a tentativa de diminuir a abrangência dos conflitos, reduzindoos a uma dimensão de maior proximidade e poder de atuação. Assim a integração Enfermagem - contexto estaria voltada à seleção do objeto de atuação - hospital - comunidade. O cuidar é evidenciado em diferentes perspectivas: da doença; da pessoa; sob a ótica da saúde coletiva. administrar ressaltando a divisão do trabalho com a equipe, evidenciando o reconhecimento da prática compartilhada.

As condutas objetivas de ação, agora já vivenciadas por todas as alunas, deixam definitivamente de ser uma referência discursiva para constituirem o elemento mais citado enquanto moduladores de possibilidades e de opçōes profissionais. Passam a ser parte integrante do processo de formação, projetando formas de adaptação e de adequação ao mundo profissional.

Essa reapresentação da totalidade na mente se sobrepõe aos conteúdos teóricos utilizados na produção do sentido de transcendência, inserindo a Enfermagem em um macrocontexto social, tanto na perspectiva da compreensão do processo saúde-doença quanto na fundamentação de ações coletivas. Para esses estudantes, programas e ideologias comporiam abordagens, por ora, pouco referidos, em decorrência talvez da necessidade de limitar responsabilidades, tornando a perspectiva do ser profissional mais pertinente aos próprios limites.

Os resultados até então obtidos evidenciaram um processo de formação que vem avançando na perspectiva da aquisição de conteúdos teóricos, conformando um processo de aprimoramento intelectual apto a direcionar projetos seletivos quanto à alocação profissional, considerando cenário e performance.

Entretanto, essa aquisição não estaria avançando para além desse campo de percepções, não expressando elaborações que, apesar de teóricas, apontassem para propostas operacionais no sentido da superação dos limites de ação referidos. Identificamos nos discursos uma sensação predominante, ainda que não hegemônica, de um eu fragilizado frente a um contexto supervalorizado enquanto poder impermeável às modificações e aos projetos pessoais. Emergem um sofrimento, um desapontamento e um conformismo na medida em que expectativas e desejos pregressos, relativos a um cuidar ou a um administrar idealizados, vão se inviabilizando. Os limites mais significantes para as alunas relacionam-se: à falta de recursos humanos; à adesão a uma rotina burocratizada e fragmentada, respaldada pela filosofia da instituição que permite essa forma de cuidar; por uma proposta de sistematização alternativa ao cuidar taylorizado que não avança para além da Escola; pelo desgaste e sofrimento decorrentes da interação com pacientes com tantos problemas. Para a maioria delas, a intensidade e complexidade desse contexto teria um poder paralisante $e$ insuportável. 
Essa percepção não viria atrelada a processos de reelaborações dessas construções cognitivas relacionadas às possibilidades de atuação. Em decorrência, o aprendizado não estaria transcendendo à dimensão das percepções. Na medida em que conceitos não se internalizam, não mobilizam sentimentos e näo reelaboram expectativas e reações, não estaria havendo uma construção capaz de sustentar proposições e ações calcadas no real decodificado.

Nesse sentido, a não reelaboração de demandas simbólico - afetivas pregressas, bem como a expressão de sistemas de elaborações teóricas ainda sincréticas sustentariam um processo de formação de estudantes ameaçados, tanto pela intensidade dos desafios quanto pela fragilidade de projetos pessoais inovadores. Assim, as possibilidades de superação manifestas dependeriam, primordialmente das condições materiais do campo e da disponibilidade da equipe profissional em aceitar mudanças. Merece destaque um depoimento que valorizou o investimento pessoal como requisito transformador. Para essa estudante, a vontade, a fundamentação e o conhecimento seriam condições potencializadoras de mudanças, tanto no sentido de reconhecer contextos como também de implementar um cuidado individualizado e sistematizado, respaldado em um sentimento de adesão ao cuidar fundamentado, especifico do enfermeiro. Sem desqualificar a complexidade conjuntural, houve uma mobilização no sentido de reconhecer-se como sujeito nesse interjogo.

Mais uma vez, manifesta-se uma atitude de passividade sem gestos de enfrentamentos, sustentando a hipótese de uma postura pessoal desinstrumentalizada para ousar, para propor, para investir no imediato com força de transformação. Em decorrência, o contexto seria representado enquanto elemento determinante e deterministico. Nesse sentido, a interação eu - contexto seria uma construção também calcada em fantasias na medida em que anula a intencionalidade dos sujeitos e hiperestima o poder da estrutura que, apesar de intenso, por ser uma construção humana, é também determinado por pessoas reais.

Assim sendo, pelo interdito de demandas e de bagagem cognitivo - simbólico - afetivas pregressas sustentando esquemas de repactuação ainda incipientes acerca do ser profissional teriamos um processo de formação, que, ao final do $3^{\circ}$ ano de graduação, $6^{\circ}$ semestre letivo, ainda convive com sistemas de conceitos sincréticos e com sistemas teórico - operacionais ainda não organizados enquanto expressăo de esquemas pessoais de atuação.

Evolutivamente, após terem cursado as 4 áreas temáticas, assim como disciplinas do $7^{\circ}$ semestre letivo - que complementam tanto os conteúdos e práticas assistenciais (UTI e saúde coletiva) como o administrativo - a crise expressa pelas estudantes se relativisa. A intensidade dos conflitos produziu respostas no sentido de abafar tensōes externas pela revalorização de atributos pessoais da dimensão pessoal - agregando valores, qualidades e vínculos - e pela expansão de papéis - com ênfase na administração como instrumento ordenador do espaço ainda que não do cuidar. A reelaboração do ser enfermeiro agrega uma exacerbação na perspectiva da assimilação do caráter polivalente, 
em sintonia com a percepção de demandas da prática, fundamentado em conhecimento e em experiência enquanto instrumento para a obtenção de reconhecimento e de autonomia considerados como imprescindíveis à identidade profissional. Os depoimentos expressam otimismo, uma valorização de aptidões e, fundamentalmente, uma sintonia prazerosa com a abrangência da ação sobre as coisas (o ambiente hospitalar; as condições de vida) e sobre pessoas (usuário - funcionário), ainda que em detrimento do cuidado direto (conflito persistente). A sintese dessas expressões encontra-se relatada a seguir.

Esquema 4: Enfermagem e contexto: selecionando projetos de ser profissional

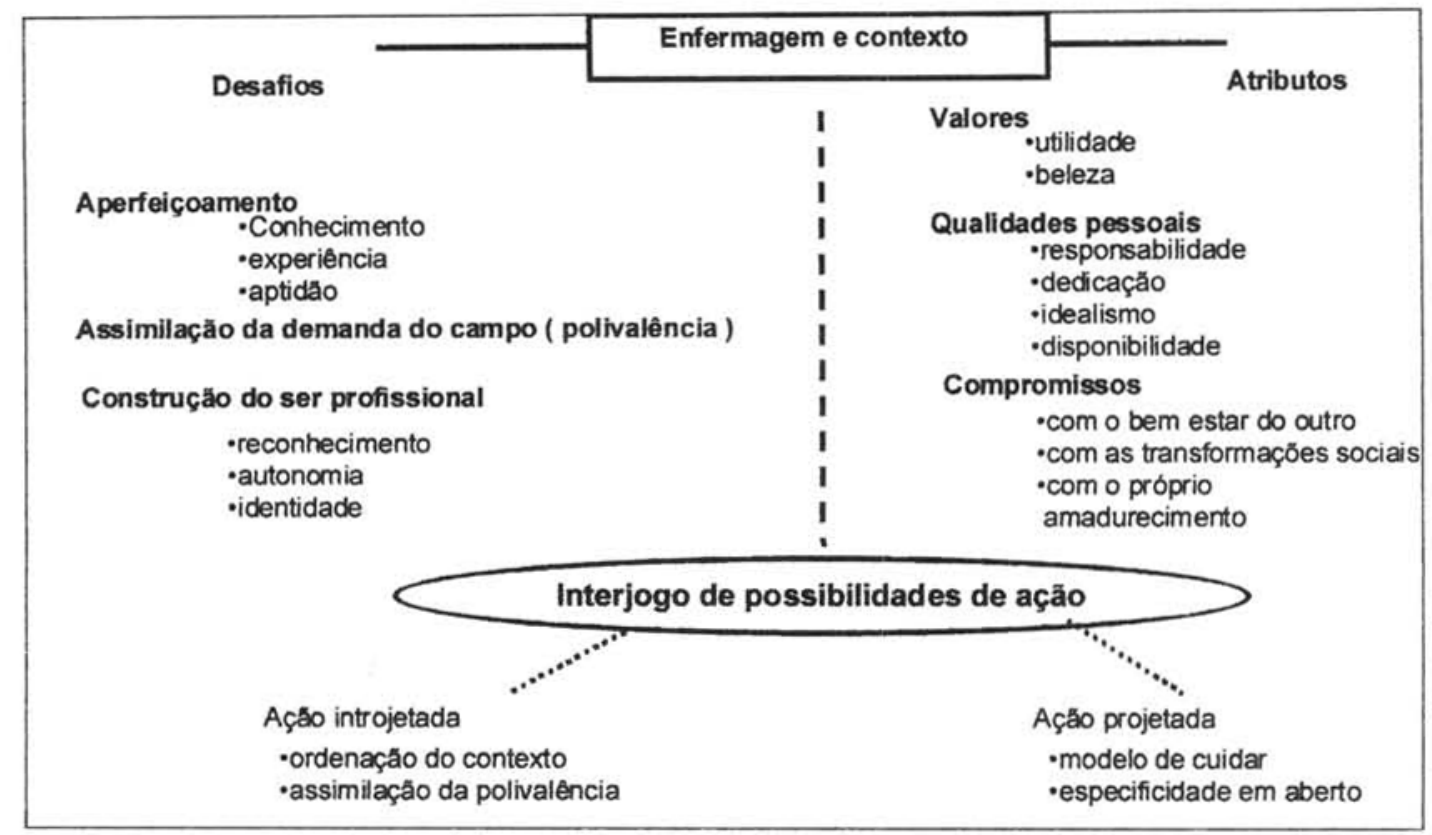

\section{CONSIDERAÇÕES FINAIS}

O projeto desenvolvido no sentido de identificar a trajetória evolutiva do processamento de conceitos enquanto natureza de apreciações, de valores e de ações expressa uma transição no padrão de significação e de representações discentes acerca da profissão e de suas relações, assim sintetizada:

- convívio com as áreas temáticas (enfermagem na saúde da criança, mulher, do adulto) aprofunda a percepção da crise profissional, tanto no que se refere às condições de trabalho quanto no reconhecimento dos vazios de apreciação, de relacionamento, de fundamentação e de especificidade de atuação enquanto marcadores de vulnerabilidade inclusive de perspectivas de ação. O núcleo relacionado à conformação da ação agrega ambos os objetos (cuidar - administrar); o método como viabilidade dependente da 
superação das rotinas e uma fundamentação teórica que, tendo a clínica como recurso, deverá avançar para além desse modelo na tentativa de chegar a um ser biopsicossocial tendo a ele como referência e a educação à saúde como instrumento privilegiado. Outro núcleo temático significante agrega atributos valorativos reconhecidos como dependentes da superação de limites.

- a partir dessa etapa, esgotam-se os argumentos que evoluem na perspectiva de polarizar apreciações mais contundentes e críticas acerca do contexto de prática, investido de um poder determinante e cristalizado na crise. Nele, o trabalho do Enfermeiro é representado em seus limites relacionados ao processo de cuidar e ao processo de se relacionar. No campo do ideal, projeções com caráter de superação vêm atreladas à valorização do método, da seleção do objeto enquanto principios norteadores do espaço profissional na sua relação com os demais. Entretanto, há um desencanto e uma expressão de impotência, configurando manifestações frágeis, na defensiva, amedrontadas frente à estrutura. Essa relação eu - contexto passa a ser o núcleo sintese, sendo hegemonicamente focado na macrodeterminação frente a estudantes que, terminando a graduação, reconhecem-se como desinstrumentalizados para bancar projetos transformadores. Frente a conceitos ainda sincréticos emerge o vazio de sistemas teórico-operacionais na perspectiva de sustentar novos esquemas de atuação frente aos limites maximizados.

- a superação da crise passa a ser o núcleo modulador de representações e de apreciações ao final do $7^{\circ}$ semestre. Nesse encadeamento conceitual, o processamento caminha no sentido de re - conhecer e de revalorizar tanto as aptidões pregressas quanto a busca do conhecimento aderido à experiência, expressando uma concepção de profissão de caráter vocacional transformado dirigida para uma ação ordenadora sobre o contexto (hospital equipe) e sobre as pessoas (doentes - equipes), já que permanece o cuidar individual, que continua sem projetos operacionais. Para as estudantes, essa situação mobiliza diferentes emoções centradas no otimismo frente ao eu novamente requerido, prazer pela percepção de uma ação ampliada e conflito frente a um cuidar ainda não processado.

Como sintese dessa trajetória de profissionalização, identificamos um desenvolvimento peculiar de esquemas conceptuais formalizados mediante estruturas que evoluiram tendo o sistema formador e o sistema utilizador de recursos humanos como referência, promovendo perspectivas distintas de atuação profissional. Tendo a graduaçăo como baliza, a especificidade profissional emerge como o desafio a ser enfrentado no sentido de dar consistência teórico-operacional ou a um dos modelos assistenciais - o clínico, o epidemiológico e o que valoriza a interação interpessoal - ou ao modelo administrativo a ser firmado tendo o controle da coisas e de pessoas como objetivo. Sob o prisma do sistema utilizador, a assimilaçăo da inespecificidade assim como a acomodação à pulverização das atividades em detrimento de uma identidade profissional própria passam a ser os requisitos de pertinência e de adesão às demandas do campo. Essa tendência se viabiliza tanto pela contenção da crítica quanto pela valorização dessa "polivalência" com estatuto de supremacia às demais atuações profissionais. 
Nesse sentido, os núcleos constituintes de cada etapa de concepção expressaram uma estrutura lógica e incorporada à construção posterior, configurando uma evolução determinada pela adesão seletiva das estudantes à graduação ou ao campo de prática. Houve ainda um movimento à margem desses dois sistemas de referência decorrente da discrepancia entre essas experiências e os esquemas pessoais, inviabilizando a assimilação das informações apresentadas. Esse avanço na transição do ser estudante para o ser profissional encontra-se expresso a seguir.

Esquema 8: O processamento da identidade profissional: as distintas possibilidades de ser Enfermeiro

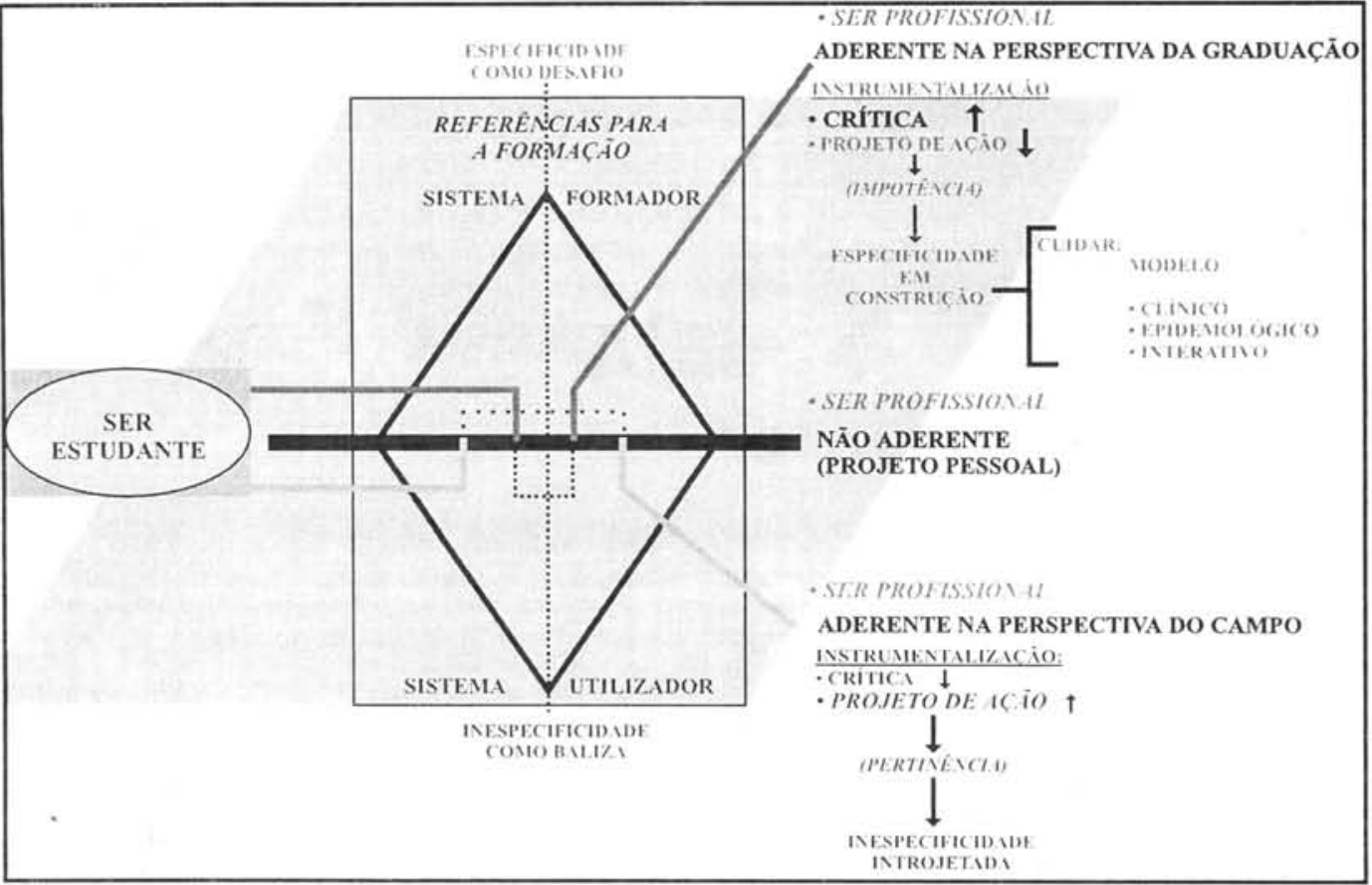

Como já analisado anteriormente, podemos considerar que o avanço cognitivo na expressão dos sistemas conceituais decorrem tanto da incorporação de novas informações e de novas vivências profissionais aos esquemas pregressos investidos de poder transformador do vir a ser profissional assim como a reiteração dessas mesmas estruturas apriorísticas formalizada pela não adesão ao sistema de referências, perpetuando a mesma maneira de enfocar e de estruturar o pensamento e a ação.

Concomitantemente, e em decorrência desse contexto, seria provável que a interação do aluno com essa diversidade de ideários induziria distintos perfis de adesão, numa gama de possibilidades que oscilaria desde a não identificação a quaisquer das perspectivas identificadas, perpetuando a reiteração de demandas, princípios e de expectativas de intervenção no contexto profissional vinculadas a significações ainda pautadas no senso comum, em esquemas de representação espontânea acerca da Enfermagem. Nesse sentido, a Graduação 
teria, em si mesma, sua força inativada pela diversidade de mensagens. Haveria, também, possibilidades de adesões parciais, decorrentes de uma maior sintonia entre a bagagem e o capital cultural desse aluno e os esquemas moduladores específicos dos diferentes padrões de poder - açăo. Haveria, aqui, tanto a vantagem de uma adesão por identidade, por paixão $e$, portanto, por envolvimento afetivo e efetivo, como também a desvantagem de transposição do mesmo modelo privilegiado a outras condições e contextos de prática nem sempre compativeis com o padrão interiorizado. Haveria ainda a forma mais esperada de adesão ao ideário da Graduação, ou seja: a possibilidade desse estudante, dependente da própria capacidade de auto-elaboração do processo de transformação dessa abordagem sincrética numa elaboração síntese do que seria o poder - ação do enfermeiro no âmbito da Enfermagem e da saúde, superar a diversidade de códigos e de mensagens, processando, ele próprio, um padrão peculiar de atuaçăo. Assim sendo, esse reprocessamento de conformação profissional transcenderia aos limites induzidos pelo sistema formador, pela potencializarão de uma bagagem intelectual aprimorada desse discente.

Frente a esse cenário e tendo como referência a realidade subjacente ao nosso sistema formador no âmbito da graduação, evidenciamos estágios de estudantes de enfermagem expressos a partir de esquemas de conceitos e de projetos de ação pautados em diferenças pessoais e em distintas possibilidades de processar a própria identidade profissional

\section{REFERÊNCIAS BIBLIOGRÁFICAS}

1. BARDIN, L. Análise de conteúdo. Lisboa: Ediçōes 70, 1977.

2. BORDIEU, P.; PASSERON, J. C.. A Reprodução: elementos para uma teoria do sistema de ensino. Rio de Janeiro: Francisco Alves, 1996.

3. IDE, C. A. C. et ali. Enfermagem e o processo de ensino aprendizagem, São Paulo, 1995./ Projeto Mimeografado/.

4. IDE, C A. C.; NODA, K.. O Processamento do conceito Enfermagem: a especificidade profissional em construção / Trabalho Apresentado na 2. Jornada Nacional de Iniciação Científica da 47. Reunião Nacional da SBPC, São Luis, 1995/.

5. NAKAMAE, D. D.. Mudanças no perfil do estudante da Escola de Enfermagem da Universidade de São Paulo em quinze anos: 1973 1988. São Paulo. Escola de Enfermagem, 1989.

6. RATNER, C.. A psicologia sócio - histórica de Vygotsky. aplicações contemporâneas. Porto Alegre: Artes Médicas, 1995.

7. RODRIGUES, A. M.. Operário, operária: estudo exploratório sobre o operariado industrial da grande São Paulo. São Paulo: Símbolo, 1978.

8. VYGOTSKY, L. S.. Pensamento e Linguagem. São Paulo: Martins Fontes; 1991.a

9.

A Formaçāo social da mente: o desenvolvimento dos processos psicológicos superiores. São Paulo: Martins Fontes; 1991.b 